\title{
Germinação e crescimento in vitro de Epidendrum secundum Jacq. (Orchidaceae) em diferentes meios de cultivo e períodos de exposição a agentes desinfestantes seminais
}

\author{
Victor Ramos Cavalcante, Larissa Borin \& Cristiano Pedroso-de-Moraes
}

Centro Universitário Hermínio Ometto, Av. Dr. Maximiliano Baruto, 500, Jd. Universitário, Araras, CEP 13607-339, São Paulo, Brasil. cpmoraes@gmail.com

Recebido em 08.X.2016

Aceito em 01.VIII.2018

DOI 10.21826/2446-8231201873212

RESUMO - Epidendrum secundum Jacq. é uma orquídea comercializada e utilizada em ornamentação, portanto, o cultivo in vitro caracteriza-se como uma técnica importante, pois proporciona rapidez, redução de custos e maior produtividade. O presente trabalho avaliou a germinação de sementes e o crescimento in vitro de $E$. secundum, oriundas de autopolinização, em três meios de cultivo distintos, MS formulado com a metade da concentração de macronutrientes, meio Kyoto e meio à base de fertilizante comercial Peters ${ }^{\circledR}$ (NPK 09-45-15) a 2 g.L L $^{-1}$. As sementes foram expostas a hipoclorito de cálcio e hipoclorito de sódio a 5\% para desinfestação por: 2,5; 5; 7,5 e 10 minutos. Ao final do experimento, a análise estatística das variáveis avaliadas, evidenciou que a interação entre uso do hipoclorito de cálcio como substância desinfestante, nos períodos de exposição de 5 e 10 min., com o meio

MS 1/2 macronutrientes são os mais indicados para o cultivo in vitro da espécie.

Palavras-chave: germinação assimbiótica, micropropagação, hipoclorito de cálcio

ABSTRACT - In vitro germination and growth of Epidendrum secundum Jacq. (Orchidaceae) in different culture media and periods of exposition to seminal disinfectant agents. Epidendrum secundum is an orchid commercialized and used for ornamental purposes; thus in vitro culture is highly important, since it is fast, low cost and has high productivity. This work evaluated the in vitro germination and growth of $E$. secundum, derived from self pollination in 3 distinct culture media: MS formulated with half macronutrient concentration, Kyoto medium and a medium formulated with Peters ${ }^{\circledR}$ fertilizers, a commercial fertilizer (NPK 09-45-15) at 2 g.L $\mathrm{L}^{-1}$. The seeds were exposed to calcium hypochlorite (5\%), sodium hypochlorite (5\%) for disinfection over $2.5 ; 5 ; 7.5$ and 10 minutes. At the end of the experiment, we found that the interaction between the use of calcium hypochlorite $(5 \%)$ as a disinfectant, in 5 and 10 min. exposure time, with MS $1 / 2$ macronutrients are the most suitable for the in vitro cultivation of this species.

Keywords: asymbiotic germination, in vitro germination, calcium hypochlorite

\section{INTRODUÇÃO}

A família Orchidaceae apresenta na atualidade 26.972 espécies reconhecidas (Pridgeon 2014), divididas em aproximadamente 800 gêneros (Atwood 1986, Pridgeon 2014), dentre os quais se destaca a subfamília Epidendroideae e o gênero neotropical Epidendrum L. por apresentar-se como um dos mais expressivos ecológica e horticulturalmente, possuindo cerca de 1.000 espécies, com distribuição pela América Latina (Chen et al. 2002). Mesmo com toda a relevância ornamental do gênero, produtores de Epidendrum encontram dificuldades no desenvolvimento da cultura, como custos elevados e taxa de propagação sexual e vegetativa muito lenta para a produção em larga escala (Chen et al. 2002).

Epidendrum secundum Jacq., possui hábito terrestre e/ ou rupícola (Caiafa \& Silva 2005) e é uma das espécies mais significativas e populares do gênero, sendo comercializada como flor de corte e de vaso e, amplamente utilizada na produção de híbridos multifloros, fato este decorrente da ampla capacidade autogâmica da espécie (Pansarin \& Amaral 2008, Massaro et al. 2012). Tal espécie foi considerada altamente polimórfica recentemente, apresentando entre suas populações ampla variação morfológica (Pinheiro \& Barros 2007).

Para aumentar e aperfeiçoar a produção de mudas com alta qualidade genética, o cultivo in vitro vem sendo empregado e a simplificação de meios de cultura surge como alternativa para reduzir os gastos na produção (Stancato 2001, Pedroso-de-Moraes et al. 2009a, 2009b; Silva et al. 2014, Gollo et al. 2016), pois a formulação dos meios de cultivo, para a propagação de orquídeas, pode ser feita de acordo com as necessidades de cada espécie (Faria et al. 2002). Muitos meios vêm sendo produzidos com o acréscimo de fertilizantes comerciais para facilitar sua preparação (Pedroso-de-Moraes et al. 2009a, 2009b). Tal facilitação foi apontada em estudo comparativo entre os meios MS (Murashige \& Skoog 1962), Knudson C 
(Knudson 1946), Vacin \& Went (Vacin \& Went 1949) e à base de fertilizantes NPK (10-5-5) e (10-30-20), para os quais muitas das variáveis fitotécnicas analisadas para as espécies Catasetum fimbriatum Lindl. e Cyrtopodium paranaensis Schult. mostraram-se mais satisfatórias em comparação às formulações comumente utilizadas para orquídeas (Oliveira \& Faria 2005).

Além desses meios de cultivo convencionais, outras alternativas têm sido desenvolvidas como a formulação de meios de cultura desenvolvidos a base de vinhaça (i.e., efluente originado da produção do etanol de canade-açúcar), os quais além de promover a redução de custos, por utilizarem grande parte dos nutrientes minerais da vinhaça, também são ecologicamente corretos devido a ser uma nova forma racional de descartar a vinhaça, que é um resíduo extremamente poluente ao meio ambiente (Silva et al. 2014, Gollo et al. 2016).

A nutrição balanceada nas fases iniciais de desenvolvimento proporcionam às plantas cultivadas in vitro alto vigor fisiológico, traduzido em maior resistência a patógenos e às adversidades do meio ambiente, além do rápido crescimento. Deste modo, a composição do meio de cultura e o agente desinfestante de sementes são de expressiva importância para a germinação e o crescimento de plantas (Kerbauy 1997). Sob está ótica, a desinfestação é indispensável em cultivo in vitro, visto que a presença de microrganismos como fungos e bactérias acarretam sérios problemas de produtividade, dentre eles a má formação das plântulas e inclusive a morte das mesmas (Hartmann \& Kester 1978, Patricio et al. 1995).

Diante do exposto, o presente trabalho teve como objetivo comparar a eficiência dos meios de cultivo MS (Murashige \& Skoog 1962), com metade da concentração de macronutrientes, Kyoto (Kano 1965) e de meio à base do fertilizante comercial Peters ${ }^{\circledR}$, bem como a influência de diferentes períodos de exposição a dois agentes desinfestantes, na germinação e desenvolvimento in vitro de plântulas de E. secundum.

\section{MATERIAL E MÉTODOS}

\section{Material botânico}

Morfologicamente a espécie se caracteriza por possuir folhas dísticas, coriáceas, ovadas a lanceoladas e planas de ápice arredondado a agudo, rizoma curto e caule cilíndrico pendente. As inflorescências são do tipo corimbo apresentando de 16 a $57 \mathrm{~cm}$ de comprimento com variação de 12 a 80 flores, podendo ser mais compridas que o próprio caule. As flores, geralmente mantendo um padrão no tamanho, apresentam sépalas e pétalas variando entre lilás e rosa. O labelo é plano, delgado, trilobado, apresentando lobos laterais suborbiculares a deltoide de margem recortada com lobo mediano retangular a deltoide de margem denticulada e ápice levemente mucronulado, apresentando coloração alva e/ou amarela (Pedroso-de-Moraes et al. 2009b). A floração ocorre entre setembro e janeiro (Dodson \& Frymire 1961, Dodson 1962, Pansarin \& Amaral 2008).
Para a realização deste trabalho, cinco flores de diferentes indivíduos terrícolas de Epidendrum secundum foram previamente autopolinizadas artificialmente em Agosto de 2012. Um semestre após a autopolinização, foram coletadas cápsulas maduras, as quais foram levadas ao Laboratório de Botânica e Análises Ambientais do Centro Universitário Hermínio Ometto - UNIARARAS para o início dos experimentos germinativos.

\section{Preparo dos meios de cultivo}

Foram preparados três meios de cultura distintos, sendo o primeiro composto por metade da concentração de macronutrientes e totalidade de micronutrientes e vitaminas do meio MS (Murashige \& Skoog 1962), o segundo pelo meio Kyoto (Kano 1965) e, o terceiro à base do fertilizante Peters $^{\circledR}$ (NPK 09-45-15) a 2 g.L. $L^{-1}$. Todos os meios foram acrescidos de 1 g.L. $\mathrm{L}^{-1}$ de carvão ativado, 30 g.. $\mathrm{L}^{-1}$ de sacarose com $\mathrm{pH}$ ajustado para $\mathrm{pH} 5,8$ antes da adição de 7 g.L. $\mathrm{L}^{-1}$ de ágar-banana. Posteriormente, $50 \mathrm{~mL}$ de cada meio de cultura foram vertidos em quatro frascos de $250 \mathrm{~mL}$ e esterilizados em autoclave a $121^{\circ} \mathrm{C}$ e 1 kgf.cm ${ }^{-2}$ de pressão durante 20 minutos (Arditti \& Ernest 1992).

\section{Desinfestação e semeadura}

As sementes foram desinfestadas mediante a agitação constante em tubos eppendorf ${ }^{\circledR}$ pelos períodos de 2,5; 5,0; 7,5 e 10 minutos em soluções de hipocloritos de sódio e de cálcio a 5\%. Em seguida, os tubos contendo as sementes foram mergulhados em álcool $70 \%$ por 5 minutos e levados à câmara de fluxo laminar, onde as sementes foram lavadas três vezes em água destilada com o auxílio de seringa de 1 $\mathrm{mL}$ (Pedroso-de-Moraes et al. 2009b). As sementes, então, após decantação nos eppendorf ${ }^{\circledR}$, foram depositadas nos frascos contendo os meios de cultivo com a assistência de uma seringa e $1 \mathrm{~mL}$ de água destilada (Arditti \& Ernest 1992). Foram semeados 10 frascos por tratamentos sendo inoculadas, por recipiente, $0,01 \mathrm{~g}$ de sementes (Pedroso-deMoraes et al. 2009b). Os frascos semeados foram fechados com tampa plástica transparente. Posteriormente estes foram mantidos durante 180 dias em câmara climática (B.O.D. MA 403), à temperatura constante de $25^{\circ} \mathrm{C}$, sob fotoperíodo de 12 horas e intensidade luminosa de aproximadamente $116 \mu \mathrm{mol} \cdot \mathrm{m}^{-2} \mathrm{~s}^{-1}$.

\section{Variáveis analisadas e análise estatística}

Após 180 dias de cultivo foram avaliados os parâmetros relacionados à quantidade de frascos contaminados, à germinação e crescimento. A porcentagem de Frascos Contaminados ( $\mathrm{PFC} \%$ ) foi estimada utilizando-se a totalidade dos frascos. Para a obtenção de todos os demais dados, foram usados quatro frascos escolhidos aleatoriamente, contendo um $0,01 \mathrm{~g}$ de sementes (Pedrosode-Moraes et al. 2009a, 2009b), sendo então avaliados a Germinabilidade ( $\mathrm{G} \%$ ) até 100 dias de cultivo in vitro (sendo considerada como planta germinada aquela que apresentou expansão foliar), Índice de Velocidade de Germinação 
(IVG) (Labouriau \& Agudo 1987), Comprimento Total da Plântula (CTP), Comprimento da Maior Raiz (CMR) e da Maior Folha (CMF), Diâmetro do Pseudobulbo (DP), Peso da Matéria Fresca (PMF) e Seca da plântula inteira (PMS), Número de Folhas (NF) e de Raízes (NR), utilizando paquímetro digital (Digimess 100A) e balança analítica (Gehaka BG 400) (Pedroso-de-Moraes et al. 2009b).

Após os testes de homegeneidade dos dados e a realização de ANOVA, com resultado significante, os dados obtidos foram submetidos à análise de regressão polinomial utilizando-se o aplicativo estatístico BioEstat 5.3. Para escolha do modelo de regressão que melhor se ajustasse aos dados observados, levou-se em consideração o fato de o desvio da regressão ser não significativo e o modelo de maior ordem apresentar grau significativo e, por último, o valor do coeficiente de determinação $\left(\mathrm{R}^{2}\right)$ (Fernandes et al. 2012).

\section{RESULTADOS}

\section{Porcentagem de frascos contaminados (PFC\%)}

De todos os frascos semeados apenas os meios Kyoto com sementes desinfestadas com $\mathrm{NaClO}$ por período de 2,5 minutos e MS, composto por metade da concentração de macronutrientes, desinfestado com $\mathrm{Ca}(\mathrm{ClO})_{2}$ por período de 7,5 minutos apresentaram $20 \%$ de contaminação fúngica.

\section{Variáveis analisadas}

Com relação às variáveis analisadas (Fig. 1), podese constatar que para a $\mathrm{G} \%$, todas as substâncias e períodos de desinfestação e meios de cultivo, apresentaram elevado valor de $\mathrm{R}^{2}$, com exceção das sementes desinfestadas em $\mathrm{NaClO}$ e germinadas em meio MS formulado com a metade da concentração de macronutrientes, o qual obteve o pior resultados dentre os tratamentos $\left(\mathrm{R}^{2}=0,45, p<0,05\right)$.

Em contrapartida, os melhores resultados obtidos, com relação à substância desinfestante, foram os encontrados para $\mathrm{NaClO}$ em meio Peters ${ }^{\circledR}$ em período de 5 minutos $\left(\mathrm{R}^{2}=0,82, p<0,05\right)$ e meio Kyoto em 10 min. $\left(\mathrm{R}^{2}=0,96, p<0,05\right)$, respectivamente. Para o IVG (Figura 1), o melhor resultado obtido foi o observado para a desinfestação em $\mathrm{NaClO}$ durante 5 min., em meio de cultivo Peters ${ }^{\circledR}\left(\mathrm{R}^{2}=0,82, p<\right.$ $0,05)$, sendo o pior desempenho encontrado para a desinfestação em $\mathrm{Ca}(\mathrm{ClO})$, durante $10 \mathrm{~min}$. em meio MS 1/2 macronutrientes $\left(\mathrm{R}^{2}=0,99, p<0,05\right)$.

$A$ análise estatística relacionadas às variáveis foliares, demonstram que para NF (Figura 2), a substância desinfestante mais eficiente foi o $\mathrm{Ca}(\mathrm{ClO})_{2}$ em período de exposição de 10 min., no meio de cultivo MS $1 / 2$ macronutrientes $\left(\mathrm{R}^{2}=0,87, p<0,05\right)$ e para CMF (Fig. 2), foi observado a maior eficiência da mesma substância desinfestante e meio de cultivo, variando-se apenas o período de exposição, sendo este de 2,5 min. $\left(\mathrm{R}^{2}=1, p<0,05\right)$.
As regressões polinomiais realizadas para as variáveis radiciais apontam que para NR (Fig. 3), o meio de cultivo MS $1 / 2$ macronutrientes, apresentouse, como o mais eficaz, sendo que os maiores valores de $\mathrm{R}^{2}$ foram obtidos tanto para a desinfestação das sementes em NaClO $\left(\mathrm{R}^{2}=0,88, p<0,05\right)$, por 7,5 min., quanto para $\mathrm{Ca}(\mathrm{ClO})_{2}$ durante $10 \mathrm{~min} .\left(\mathrm{R}^{2}=\right.$ $0,99, p<0,05$ ). Entretanto para CMR (Figura 3), observou-se melhor desempenho em meio MS $1 / 2$ macronutrientes, em $\mathrm{Ca}(\mathrm{ClO})_{2}$ durante $5 \mathrm{~min} .\left(\mathrm{R}^{2}=\right.$ 0,7537, $p<0,05$ ).

Para a variável CTP (Fig. 4), as análises de regressão polinomial indicaram que o melhor resultado obtido foi para o uso do meio de cultivo MS $1 / 2$ macronutrientes, com as sementes tendo sido desinfestadas em $\mathrm{Ca}(\mathrm{ClO})_{2}$ durante $2,5 \mathrm{~min} .\left(\mathrm{R}^{2}=\right.$ $0,94, p<0,05$ ). Contudo, para DP (Fig. 4), obtevese que a desinfestação em $\mathrm{Ca}(\mathrm{ClO})_{2}$, apresentou em consonância com o meio Peters ${ }^{\circledR}$, em período de exposição de 10 min. $\left(\mathrm{R}^{2}=0,98, p<0,05\right)$, seguido do meio MS $1 / 2$ macronutrientes, por 5 min. $\left(\mathrm{R}^{2}=0,7\right.$, $p<0,05)$, os melhores resultados.

Com relação à PMF (Fig. 5), pode-se observar que o melhor resultado obtido foi para a desinfestação com $\mathrm{Ca}(\mathrm{ClO})_{2}$ durante $2,5 \mathrm{~min}$. em meio de cultivo MS $1 / 2$ macronutrientes $\left(\mathrm{R}^{2}=0,81, p<0,05\right)$. Já, para PMS (Figura 5), o uso de NaClO, no mesmo meio de cultivo e período de exposição de PMF, apresentaram os melhores resultados $\left(\mathrm{R}^{2}=0,80, p<0,05\right)$.

\section{DISCUSSÃO}

\section{Porcentagem de frascos contaminados (PFC\%)}

Um dos maiores problemas da produção em escala comercial de orquídeas é a contaminação do meio de cultivo por fungos e bactérias durante as etapas de propagação in vitro. A contaminação estabelece-se no meio competindo com o vegetal pelos nutrientes, produzindo substâncias tóxicas e inibindo o desenvolvimento (Sousa et al. 2007).

Os agentes líquidos mais comumente usados para a desinfestação seminal em cultivo in vitro de orquídeas são os hipocloritos de cálcio e sódio, pois apresentam ampla eficiência na eliminação de microrganismos (Hartmann \& Kester 1978, Agrios 1997, Faiad et al. 1997, Montarroyos 2000). Entretanto, na literatura, encontrase o uso de diferentes concentrações de hipocloritos para desinfestações, sendo descrito desde 0,4 a $5 \%$ (Alvarez-Pardo et al. 2006, Pedroso-de-Moraes et al. 2009a, 2009b, Cordeiro et al. 2011, Cunha et al. 2011, Chiapim \& Moraes 2012, Dezan et al. 2012, Massaro et al. 2012, Pedroso-de-Moraes et al. 2012). Sugere-se que o aumento na concentração dos agentes desinfestantes, apesar de apresentar maior eficiência na eliminação de microrganismos, também acarreta na diminuição do percentual germinativo (Alvarez-Pardo et al. 2006), como pode ser observado na Figura 1A. 

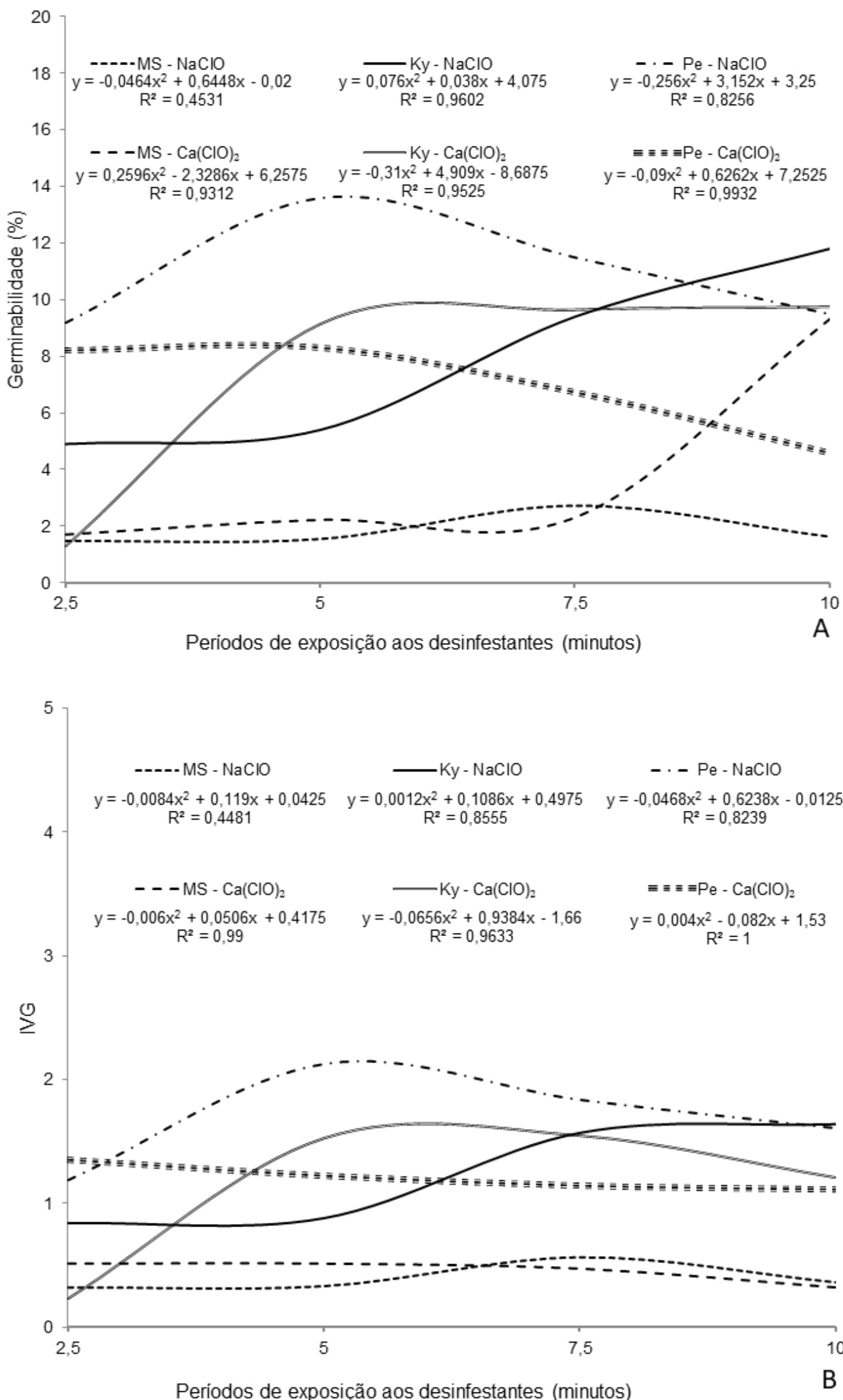

Fig. 1. Germinabilidade (G\%) e Índice de Velocidade de Germinação (IVG após 180 dias de cultivo in vitro, com relação a meios de cultivo e períodos de exposição à diferentes concentrações de $\mathrm{NaClO} \mathrm{e} \mathrm{Ca}(\mathrm{ClO})_{2}$ em sementes de Epidendrum secundum. $\mathrm{MS}=\mathrm{Meio}$ de Murashige \& Skoog (1962), Ky = Meio Kyoto de Kano (1965), $\mathrm{Pe}=$ Meio à base de fertilizante Peters ${ }^{\circledR}$. 

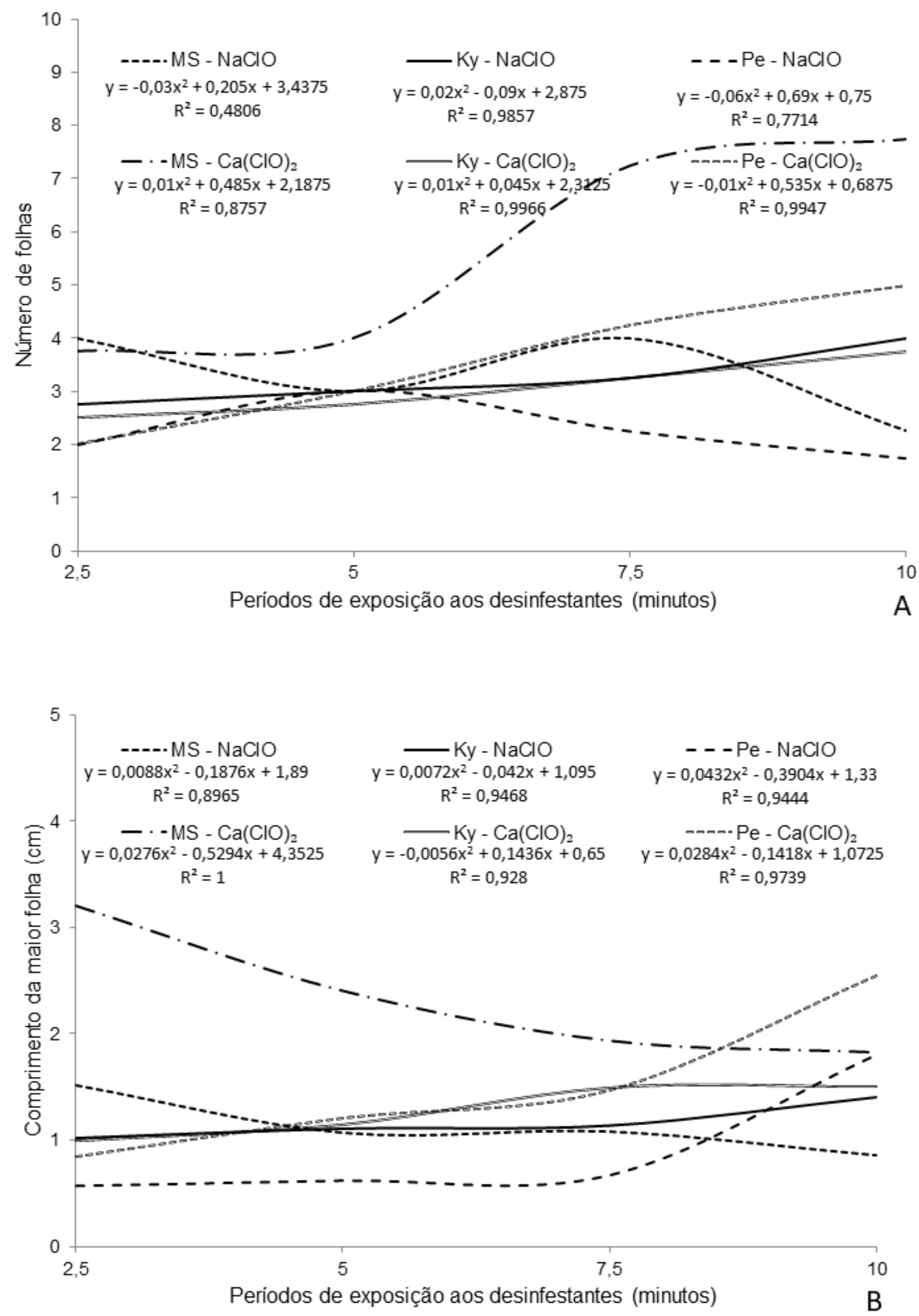

Fig. 2. Número de Folhas (NF) e Comprimento da Maior Folha (CMR), avaliadas após 180 dias de cultivo in vitro, com relação a meios de cultivo e períodos de exposição a diferentes concentrações de $\mathrm{NaClO}$ e $\mathrm{Ca}(\mathrm{ClO})_{2}$ em sementes de Epidendrum secundum. MS = Meio de Murashige \& Skoog (1962), Ky = Meio Kyoto de Kano (1965), Pe = Meio a base de fertilizante Peters ${ }^{\circledR}$. 

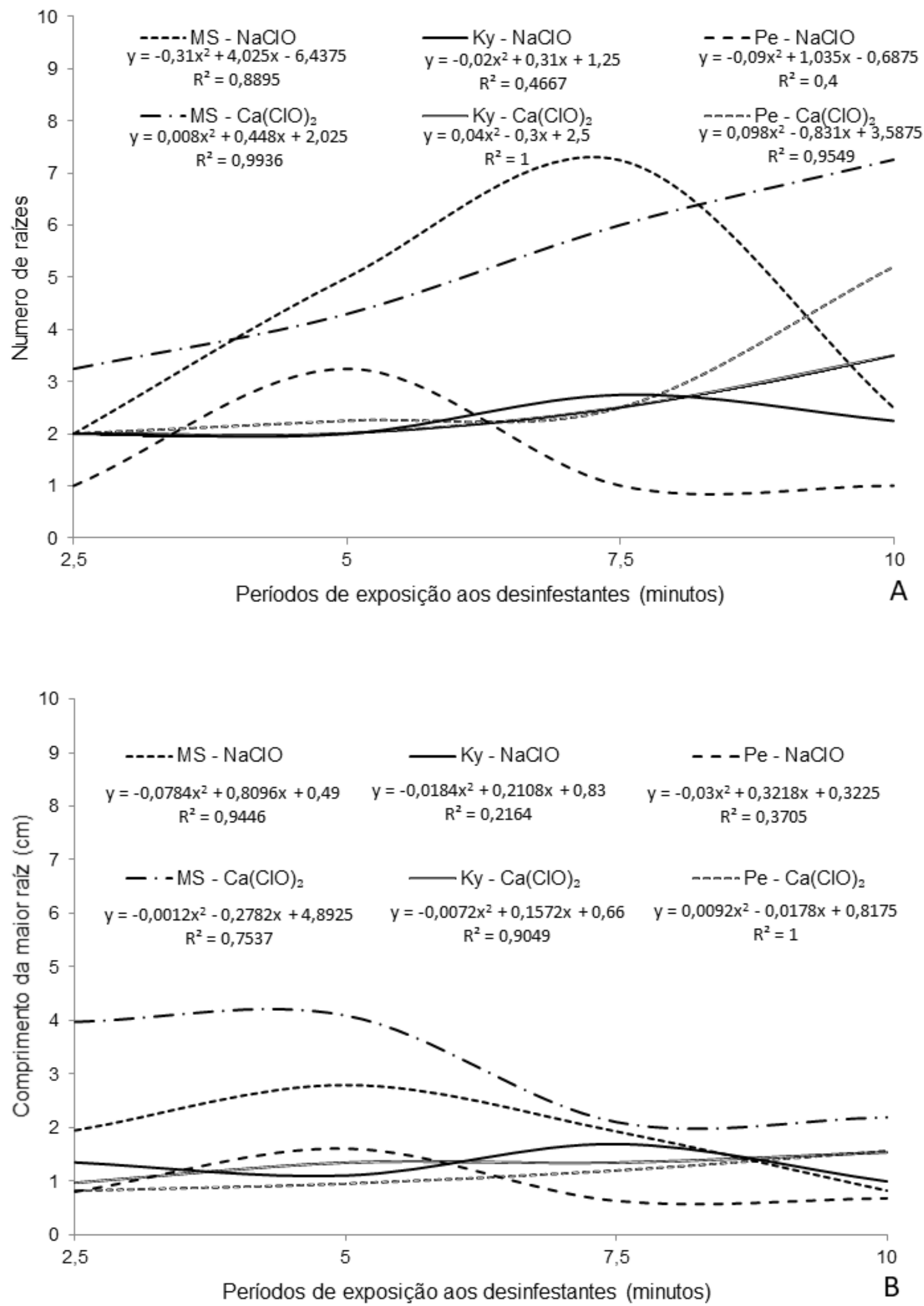

Fig. 3. Número de Raízes (NR) e Comprimento da Maior Raíz (CMR), avaliadas após 180 dias de cultivo in vitro, com relação a meios de cultivo e períodos de exposição à diferentes concentrações de $\mathrm{NaClO}$ e $\mathrm{Ca}(\mathrm{ClO})_{2}$ em sementes de Epidendrum secundum. $\mathrm{MS}=\mathrm{Meio}$ de Murashige \& Skoog (1962), Ky = Meio Kyoto de Kano (1965) e Pe = Meio à base de fertilizante Peters ${ }^{\circledR}$. 

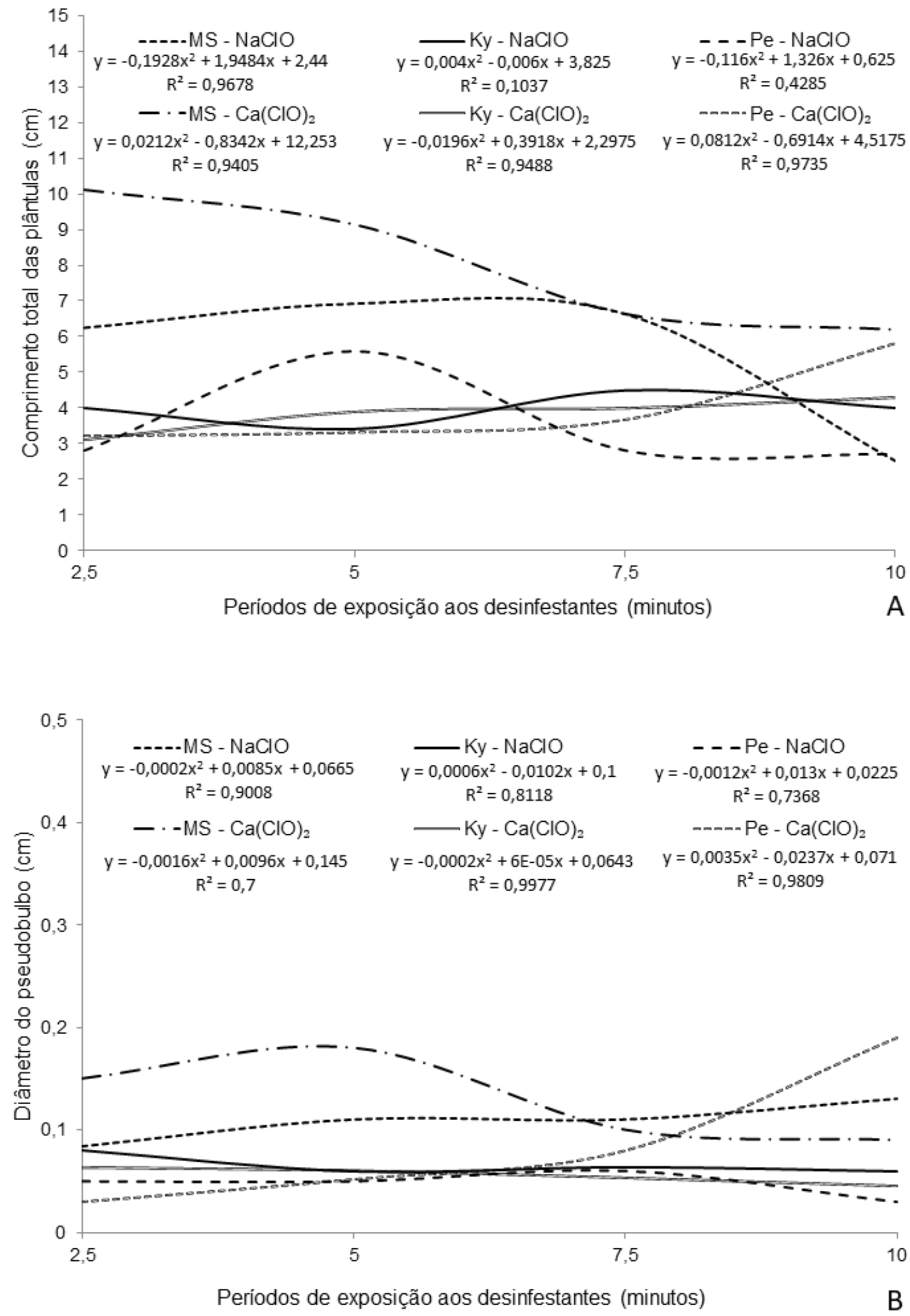

Fig. 4. Comprimento Total da Plântula (CTP) e Diâmetro do Pseudobulbo (DP), avaliadas após 180 dias de cultivo in vitro, com relação a meios de cultivo e períodos de exposição a diferentes concentrações de $\mathrm{NaClO}$ e $\mathrm{Ca}(\mathrm{ClO})_{2}$ em sementes de Epidendrum secundum. MS = Meio de Murashige $\&$ Skoog (1962), Ky = Meio Kyoto de Kano (1965), Pe = Meio à base de fertilizante Peters ${ }^{\circledR}$. 

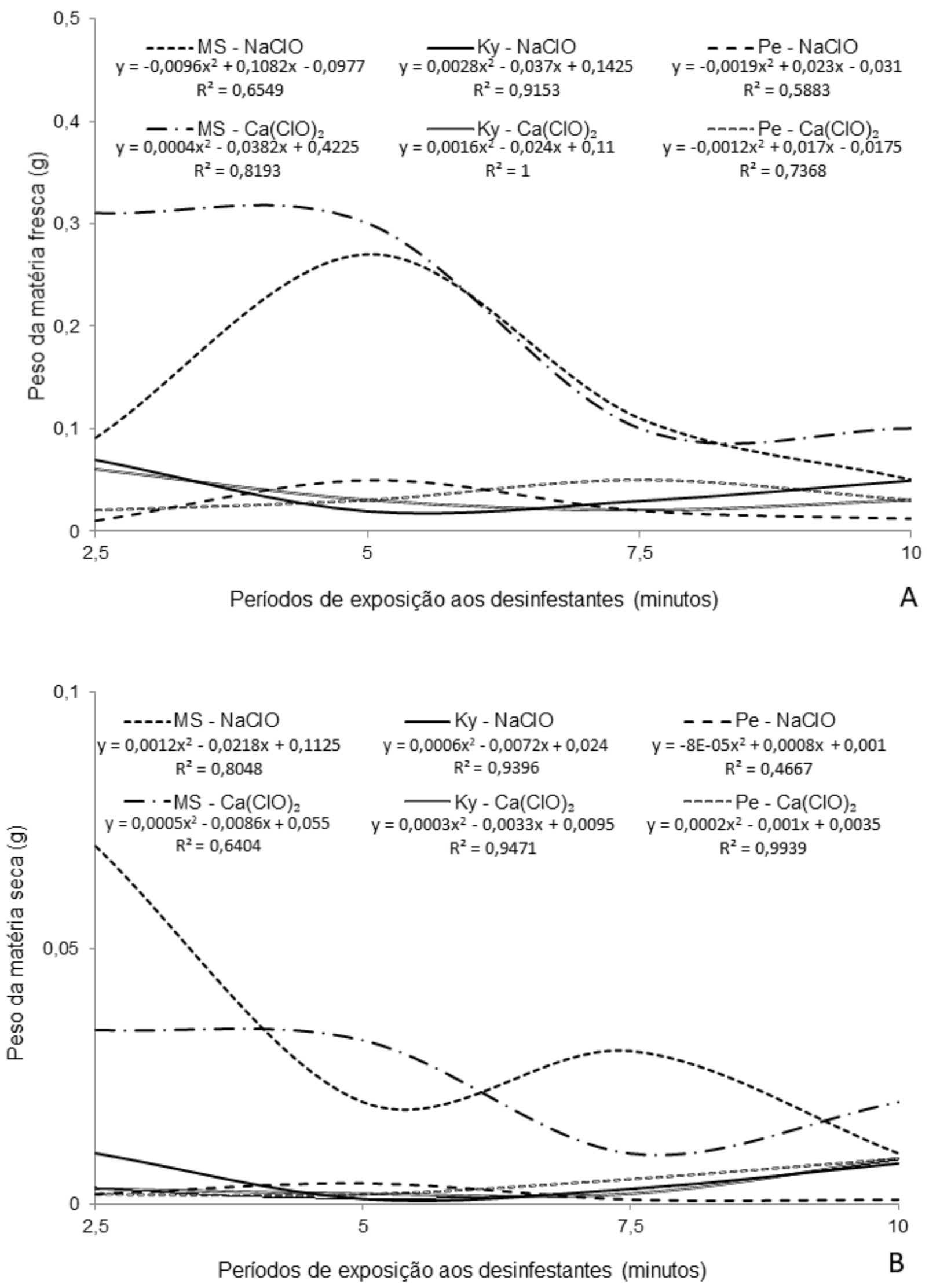

Fig. 5. Peso da Matéria Fresca (PMF) e Peso da Matéria Seca (PMS), avaliadas após 180 dias de cultivo in vitro, com relação a meios de cultivo e períodos de exposição a diferentes concentrações de $\mathrm{NaClO}$ e $\mathrm{Ca}(\mathrm{ClO})_{2}$ em sementes de Epidendrum secundum. $\mathrm{MS}=\mathrm{Meio}$ de Murashige \& Skoog (1962), Ky = Meio Kyoto de Kano (1965), Pe = Meio a base de fertilizante Peters ${ }^{\circledR}$. 
Ainda, ressalta-se, que a contaminação dos meios, neste trabalho, se deu apenas por fungos. Uma das causas desse tipo de contaminação está relacionada a cuidados no ambiente de trabalho (Sousa et al. 2007) e erros na manipulação dos meios de cultivo por parte de funcionários (Pedroso-de-Moraes 2000), sendo que, mesmo com toda a assepsia necessária sendo realizada, em biofábricas brasileiras já foram registradas porcentagens de contaminação superiores a 30\% (Oliveira et al. 2000). Contudo, o desejável para produção comercial rentável de orquídeas é da ordem de 5\% (Pedroso-de-Moraes 2000).

\section{Variáveis avaliadas}

Trabalhos apontam que não existe um meio de cultivo específico para espécies de orquídeas e que a concentração de sais, tanto pela falta quanto pelo excesso, pode influenciar no desenvolvimento de plântulas in vitro (Park et al. 2004, Figueiredo et al. 2007, Stancato et al. 2008). As interações entre os nutrientes modulam o crescimento das plantas (Marschner 1995), entretanto, o motivo pelos quais diferentes combinações de nutrientes e condições do meio cultivo podem fracassar ou serem um sucesso são de difícil compreensão (Ventura et al. 2002). Dessa forma, podem existir amplas diferenças entre as variáveis analisadas em um mesmo, ou diferentes meios de cultivo utilizados (Pedroso-de-Moraes et al. 2009a, 2009b). Com relação aos resultados obtidos, para as variáveis $\mathrm{G} \%$, IVG e DP, o meio de cultivo a base do fertilizante Peters ${ }^{\circledR}$, mostrouse o mais significativo estatisticamente. Contudo, para as demais variáveis analisadas, o meio MS $1 / 2$ macronutrientes, apresentou-se mais efetivo em detrimentos aos: Kyoto e o base do fertilizante Peters ${ }^{\circledR}$.

Com relação ao uso do fertilizante Peters ${ }^{\circledR}$ para composição de meios de cultivo, observou-se que concentrações entre 0,25 e $2,25 \mathrm{~g} \mathrm{~L}^{-1}$ (Rodrigues et al. 2012a) não permitiram a definição da melhor dose a ser adicionada à meios nutritivos. Entretanto, concentrações a partir de 2 a $6 \mathrm{~g} \mathrm{~L}^{-1}$ podem gerar efeitos benéficos para diversas variáveis analisadas (Rodrigues et al. 2012b).

A análise pormenorizada dos testes de germinação indica baixa taxa de $\mathrm{G} \%$ para todos os períodos de desinfestação nos diferentes meios de cultivo analisados (6-32\%). Dessa forma, os resultados encontrados neste trabalho, discordam dos observados para nove espécies de Cattleya Lindl., para as quais a germinação (considerada na fase de protocórmio) em meio de cultivo Knudson C, com sementes desinfestadas por 10 minutos em solução de Dicloroisocianurato de sódio (NaDCC) a 5\%, contendo 100 $\mu \mathrm{L}$ de Tween 80 , evidenciaram altas taxas de germinação, sendo a menor porcentagem encontrada para Cattleya mossiae Parker ex Hooker (68\%) e as maiores para $C$. granulosa Lindl., C. hegeriana (Campacci) Van den Berg, C. intermedia Graham ex Hook. e C. tigrina Verschaff. ex Lem. (99\%), após 35 dias de cultivo in vitro (Hosomi et al. 2012). Da mesma forma para Epidendrum fulgens Brongn., foi obtida porcentagem de germinação de $83 \%$, quando cultivada em meio Knudson C, com sementes desinfestadas com gás formol por uma hora (Alvarez-Pardo et al. 2001), também sendo considerado como germinadas sementes na fase de protocórmios.

O IVG é um indicador do vigor da semente e, alterações em seus valores (sendo acréscimos ou decréscimos) têm repercussões biológicas. Decréscimos em tal índice são os primeiros indicativos do processo de deterioramento ou indução de dormência em sementes e, portanto, prejudiciais a todo o processo germinativo (MachadoNeto \& Custódio 2005).

Para orquídeas, sabe-se que espécies pertencentes à subtribo Laellinae, geralmente, apresentam rápida germinação, como espécies de Cattleya. Entretanto, alguns representantes da subtribo apresentam maior tempo para levar a cabo sua germinação, como por exemplo, Laelia speciosa (Kunth) Schltr., a qual germina 100 dias após sua semeadura (Ávila-Diaz et al. 2009). Também, gêneros de orquídeas como Paphiopedilum Pfitzer, apresentam períodos germinativos semelhantes (Long et al. 2010). Os resultados obtidos neste trabalho apresentaram baixo IVG em relação aos obtidos para espécies de Cattleya, para as quais, o menor índice observado foi de 4,01 $\pm 0,27$ para $C$. tenuis Campacci \& Vedovello e o maior para $C$. hegeriana $(13,21 \pm 0,09)$, sendo considerado como germinação o aparecimento de protocórmios (Hosomi et al. 2012).

As baixas taxas de G\% e IVG obtidas podem ter sido ocasionadas pela autofecundação para a obtenção de sementes neste trabalho e exposição a elevadas concentrações de agentes desinfestantes de sementes.

O fenômeno da autofecundação e da endogamia culminam no declínio no número de heterozigotos com a perda ou fixação de alelos, o que pode ter influência na manutenção da diversidade genética, queda na produtividade, viabilidade de sementes, fertilidade e vigor das plantas (Crow \& Kimura 1970, Allard 1971, Mettler \& Gregg 1973, Geburek 1986, Falconer \& Mackay 1996, Kageyama et al. 1998, Sebbenn et al. 2000), mesmo com tal prática, sendo comum para a obtenção de sementes em vários trabalhos realizados com orquídeas (Pedroso-deMoraes et al. 2009a, 2009b, Cordeiro et al. 2011, Cunha et al. 2011, Pedroso-de-Moraes et al. 2012, Dezan et al. 2012, Massaro et al. 2012, Pedroso-de-Moraes et al. 2012).

Com relação à concentração de agentes desinfestantes, o hipoclorito de sódio ou de cálcio vem mostrando grande eficiência na desinfestação de sementes, eliminando fungos e bactérias, sendo que a concentração de tais agentes e, o tempo de exposição das sementes a estes compostos pode variar de acordo com a espécie, pois cada tecido seminal possui um nível de sensibilidade diferente, sendo necessária, então, a sua adequação de acordo com o tecido a ser desinfestado (Montarroyos 2000). Dessa forma, o uso de hipocloritos pode influenciar diretamente nas taxas de germinação in vitro (McCollum \& Linn 1955). A ação prolongada do hipoclorito de sódio ou sua utilização em altas concentrações pode induzir deterioramento com prejuízos à G\% e ao IVG (Ferreira \& Ranal 1999) e até mesmo, 
a dormência de sementes em algumas espécies vegetais (McCollum \& Linn 1955, Hsiao 1979, Hsiao et al. 1981). Contudo, o hipoclorito de cálcio tem sido relatado como o agente desinfestante que apresenta o menor efeito tóxico a tecidos em comparação ao hipoclorito de sódio, permitindo correta morfogênese de plântulas, principalmente, de caules (Torres et al. 1998, Ferreira \& Ranal 1999).

O resultado obtido para a variável DP é corroborado pelo bom desenvolvimento dos pseudobulbos durante a fase de aclimatização de plântulas realizada para Dendrobium nobile Lind. cv. UEL 8, submetida a adubação com $3 \mathrm{~g} \mathrm{~L}^{-1}$ da fórmula 10-30-20 (Peters $^{\circledR}$ ) (Faria et al. 2013). Entretanto, ressalta-se que para muitas orquídeas, uma das grandes limitações do fertilizante Peters ${ }^{\circledR}$ diz respeito à ausência de $\mathrm{Ca}$ em suas formulações, cujo uso, frequentemente, gera morte de gemas e brotações jovens, sintoma clássico da deficiência deste elemento (Rodrigues et al. 2002).

Os melhores resultados encontrados para as variáveis CMF, CMR, CTP, NF, NR, PMF e PMS foram observados para o meio de cultivo MS $1 / 2$ macronutrientes, corroborando com os obtidos para as Laellinae: Cattleya cinnabarina van den Berg (Stancato \& Faria 1996), Schomburgkia gloriosa Rchb. f. (Dezan et al. 2012) e E. secundun Jacq. (Massaro et al. 2012).

Ainda, a avaliação de diferentes meios de cultura: MS (Murashige \& Skoog 1962), KC (Knudson 1946), RL (Rosa \& Laneri 1977) e VW (Vacin \& Went 1949), para germinação e desenvolvimento de plântulas de Cymbidium aloifolium Lindl., Dendrobium crepidatum Lindl. \& Paxton e Epidendrum radicans Lindl., revelaram que os meios nutritivos MS e RL, respectivamente, obtiveram os melhores resultados para desenvolvimento vegetativo para as espécies estudadas (Reddy et al. 1992).

Em concordância com os resultados obtidos, temos que a utilização de meio de cultivo MS $1 / 2$ macronutrientes gerou bons resultados para as variáveis CTP, PMF e PMS, quando comparados com meios à base de fertilizantes NPK para C. fimbriatum Rich. ex Kunth. (Rego-Oliveira $\&$ Faria 2005).

O desenvolvimento do sistema radicial é favorecido pelas taxas de amônio no meio de cultivo, sendo verificado em espécies da família Bromeliaceae como Pitcairnia flammea Lindl. e Vriesea philippocoburgii Wawra. (Mercier \& Kerbauy 1991), além de espécies de Orchidaceae como Cattleya nobilior Rchb.f. (Araujo et al. 2005), o que entra em concordância com os resultados obtidos nesse trabalho para a variável CMR (Figura 2), visto que o meio MS, em comparação a outros tipos de meio de cultivo, possui altas concentrações de nitrogênio na forma de nitrato de amônio (Rodríguez et al. 2005), sendo que, N é essencial para o controle do crescimento de plantas e sua falta pode limitá-lo (Boddey et al. 1997, Vaast et al. 1998, Perin et al. 2004). Dessa forma, o meio MS mostra-se bem-sucedido no cultivo in vitro de orquídeas, mesmo que originalmente tenha sido empregado no cultivo de tecidos de tabaco (Rodríguez et al. 2005).
Em relação ao fósforo e potássio, a incorporação destes pelas plantas é proporcional ao crescimento e desenvolvimento de culturas, sendo assim, no meio MS $1 / 2$ macronutrientes, a concentração de sais fosfatados e sais contendo potássio permitem um incremento nas variáveis avaliadas, em especial às relacionadas ao sistema radicial (Massaro et al. 2012).

Em um trabalho realizado com cultivo in vitro de Cattleya lodigesii Lindl., a combinação de $\mathrm{KCl}$ e $\mathrm{K}_{2} \mathrm{SO}_{4}$ promoveu bom crescimento das plântulas, porém não foi favorável a variável CMR. Em contrapartida, na ausência de $\mathrm{K}_{2} \mathrm{SO}_{4}$ a variável CMR apresentou melhores resultados (Figueiredo et al. 2008). Isso se deve ao fato de que a absorção de um nutriente pode sofrer influência quando na presença de outro nutriente (Malavolta et al. 1997), tornando imprescindível a formulação de meios de cultivo específicos para cada espécie, visando uma melhoria no crescimento e desenvolvimento in vitro de plântulas (RegoOliveira \& Faria 2005). Mediante o exposto, pode-se concluir que o meio MS $1 / 2$ macronutrientes juntamente com $\mathrm{Ca}(\mathrm{ClO})_{2}$ como substância desinfestante de sementes, nos períodos de exposição de 5 e $10 \mathrm{~min}$., foi a combinação mais eficaz entre os tratamentos.

\section{REFERÊNCIAS}

Agrios, G. N. 1997. Plant pathology, Academic Press, University of Florida, Flórida. 635 p.

Allard, R. W. 1971. Princípios do melhoramento genético das plantas. Edgard Blucher, São Paulo. 381 p.

Alvarez-Pardo, V., Souza, F. L. \& Ferreira, A. G. 2001. Desinfestação de sementes de orquídeas. In Anais do Congresso Nacional de Fisiologia Vegetal, Ilhéus. Sociedade Brasileira de Fisiologia Vegetal. CD-ROM.

Alvarez-Pardo, V. M., Ferreira, A. G. \& Nunes, V. F. 2006. Métodos de desinfestação de sementes para o cultivo in vitro de orquídeas epífitas do Sul do Brasil. Horticultura Brasileira 24:2.

Araujo, A. G., Pasqual, M., Rodrigues, F. A., Rodrigues, V. A., \& Ferreira, A. L. 2005. Meios de cultura e $\mathrm{GA}_{3}$ no cultivo in vitro de um híbrido de orquídea. Horticultura Brasileira 2:612-615.

Arditti, J. \& Ernest, R. 1992. Micropropagation of orchids. John Wiley \& Sons, New York. 682 p.

Atwood, J. T. 1986. The size of the Orchidaceae and the systematic distribution of epiphytic orchids. Selbyana 9:171-186.

Ávila-Diaz, I., Oyama, K., Gómez-Alonso, C. \& Salgado-Garciglia, R. 2009. In vitro propagation of the endangered orchid Laelia speciosa. Plant Cell Tissue and Organ Culture 99:335-343.

Boddey, R. M., Alves, B. J. R. \& Urquiaga, S. 1994. Quantificação da fixação biológica de nitrogênio associada a plantas utilizando o isótopo $15 \mathrm{~N}$ In Manual de métodos empregados em estudos de microbiologia agrícola (M. Hungria \& R. S. Araújo - ed.). Brasília: Embrapa-CNPAF, p.471-494.

Caiafa, A. N. \& Silva, A. F. 2005. Composição florística e espectro biológico de um campo de altitude no Parque Estadual da Serra do Brigadeiro, Minas Gerais - Brasil. Rodriguésia 56:163-173,

Chen, L. R.; Chen, J. T. \& Chang, W. C. 2002. Efficient production of protocorm-like bodies and plant regeneration from flower stalk explants of the sympodial orchid Epidendrum radicans. In Vitro Cellular and Developmental Biology Plant, 38:441-445.

Chiapim, C. \& Moraes, P. C. et al. 2012. Crescimento in vitro em diferentes meios de cultura: avaliação do híbrido Brassavola perrinii Lindl. x Cattleya loddigesii Lindl. Orquidário 26:57-62.

Cordeiro, G. M., Pedroso-de-Moraes, C., Massaro, R. \& Cunha, T. 2011. Desenvolvimento in vitro de Cattleya amethystoglossa Lindley X (Cattleya dupreana X Laelia purpurata Lindley) em diferentes meios de cultura. Revista Científica Eletrônica de Agronomia 18:22-28. 
Crow, J. F. \& Kimura, M. A. 1970. An introduction to population genetics theory. Harper and Row, New York. 591 p.

Cunha, T., Cordeiro, G. M., Massaro, R., Dezan, L. F. \& Pedroso-de- Moraes, C. 2011. Desenvolvimento in vitro de Laeliocattleya schilleriana Rolfe utilizando meios de cultivo simplificados. Scientia Plena 7:1-5.

Dezan, L. F., Canassa, F., Souza-Leal, T., Diogo, J. A., Massaro, R., Cordeiro, G. M. \& Pedroso-de-Moraes, C. 2012. Crescimento in vitro de Schomburgkia gloriosa Lindl. em meio de cultivo simplificados. Idesia (Arica). 30:12-19.

Dodson, C. H. 1962. The importance of pollination in the evolution of the orchids of tropical America. American Orchid Society Bulletin 31:525-735.

Dodson, C. H. \& Frymire, G. P. 1961. Preliminary studies in the genus Stanhopea. Annals of the Missouri Botanical Garden, 48:137-172.

Faiad, M. G. R. Salomão, A. N., Cunha, R. \& Padilha, L. S. 1997. Efeito do hipoclorito de sódio sobre a qualidade fisiológica e sanitária de sementes de Commiphora lepthopholoeos (Mart.) J. B. Gillet. Revista Brasileira de Sementes, 9:4-17.

Falconer, D. S. \& Mackay, T. F. 1996. Introduction to quantitative genetics. Longman, London. $464 \mathrm{p}$.

Faria, R. T., Santiago, D. C., Saridakis, D. P., Albino, U. B. \& Araújo, R. 2002. Preservation of the brazilian orchid Cattleya walkeriana Gardner using in vitro propagation. Crop Breeding and Applied Biotechnology 2:489-492.

Faria, R. T., Takahashi, L. S., Lone, A. B., de Souza, G. R., da Silva, G. L. \& Hoshino, R. T. 2013. UEL 8: nova cultivar de Dendrobium. Horticultura Brasileira 31:509-511.

Fernandes, M. R., Barboza, M. P., de Souza-Leal, T., \& Pedroso-deMoraes, C. 2012. Morfobiometria carpo seminal e germinação de Lafoensia pacari A. St. Hil. (Lythraceae) exposta a diferentes concentrações de GA. Semina: Ciências Agrárias, 33:2571-2584.

Ferreira, W. R. \& Ranal, M. A. 1999. Germinação de sementes e crescimento de plântulas de Brassica chinensis L. var. parachinensis (Bailey) Sinskaja (couve-da-malásia). Pesquisa Agropecuaria Brasileira, 34:353-361.

Figueiredo, M. A., dos Santos, F. M., de Oliveira Costa, J., Costa, F. H. S. \& Pasqual, M. 2007.Variações no meio de cultura sobre o crescimento in vitro em híbridos de orquídea. Revista Brasileira de Biociências 5:294-296.

Figueiredo, M. A., de Araujo, A. G., Santos, K. P. J. F. C. \& Rodrigues, V. A.2008. Fontes de potássio no crescimento in vitro de plantas de orquídea Cattleya loddigesii. Ciência Rural 38:255-257.

Geburek, T. 1986. Some results of inbreeding depression in Serbian spruce (Picea omorica (Panc.) Purk.). Silvae genetic 35:169-172.

Gollo, A. L., da Silva, A. L. L., de Lima, K. K. D., Costa, J. D. L., Camara, M. C., Biasi, L. A. \& Soccol, C. R. 2016. Developing a plant culture medium composed of vinasse originating from Haematococcus pluvialis culture. Pakistan Journal of Botany 48:295-303.

Hartmann, H. T. \& Kester, D. E. 1978. Propagación de planta: principios y prácticas, Continental S.A., Buenos Aires. 810 p.

Hosomi, S. T., Custódio, C. C., Seaton, P. T., Marks, T. R. \& MachadoNeto, N. B. 2012. Improved assessment of viability and germination of Cattleya (Orchidaceae) seeds following storage. In Vitro Cellular \& Developmental Biology - Plant, 48:127-136.

Hsiao, A. I. 1979. The effect of sodium hypochlorite and gibberellic acid on seed dormancy and germination of wild oats (Avena fatua). Canadian Journal of Botany 57:1729-1734.

Hsiao, A. I., Worsham, A. D. \& Moreland, D. E. 1981. Effects of sodium hypochlorite and certain plantgrowth regulators on germination of witchweed (Striga asiatica) seeds. Weed Science 29:98-100.

Kageyama, P. Y., Gandara, F. B. \& Souza, L. D. 1998. Consequências genéticas da fragmentação sobre populações de espécies arbóreas. Série Técnica IPEF 12:65-70.

Kano, K. 1965. Studies on the media for orchid seed germination. Memoirs of the Faculty of Agriculture 20:1-68.

Kerbauy, G. B. 1997. Clonagem de plantas in vitro. Biotecnologia Ciência e Desenvolvimento 1:30-33.

Knudson, L. 1946. A new nutrient solution for the germination of orchid seed. American Orchid Society Bulletin 14:214-217.

Labouriau, L. G. \& Agudo, M. 1987. On the physiology of seed germination in Salvia hispanica L. I. Temperature effects. Anais da Academia Brasileira de Ciências 59:37-56.
Long, B., Niemiera, A. X., Cheng, Z. Y. \& Long, C. L. 2010. In vitro propagation of four threatened Paphiopedilum species (Orchidaceae). Plant Cell Tissue and Organ Culture 101:151-162.

Machado-Neto, N. B. \& Custódio, C. C. 2005. Orchid conservation through seed banking: ins and outs. Selbyana 26:229-235.

Malavolta, E., Vitti, G. C. \& Oliveira, S. A. 1997. Avaliação do estado nutricional das plantas: princípios e aplicações. 2ed. Associação Brasileira para Pesquisa da Potassa e do Fosfato, Piracicaba, SP. 319 p.

Marschner, H. 1995. Mineral nutrition of higher plants. Academic Press, New York. 888 p.

Massaro, R., Cordeiro, G. M., de Souza-Leal, T. \& Pedroso-de-Moraes, C. 2012. Desenvolvimento In Vitro de Epidendrum secundum Jaqc. Em Meios de Cultivo Simplificados. Revista em Agronegócio e Meio Ambiente 5:21-32.

McCollum, J. P. \& Linn, M. B. 1955. Bleaching and disinfecting discolored pepper seed with sodium hypochlorite. Proceedings of the American Society for Horticultural Science 66:345-349.

Mercier, H. \& Kerbauy, G.B. 1991. Effects of nitrogen source on growth rates and levels of endogenous cytokinins and chlorophyll in protocorms of Epidendrum fulgens. Journal of Plant Physiology 138:195-199.

Mettler, L. E. \& Gregg, T. G. 1973. Genética de populações e evolução. Polígono/ EDUSP, São Paulo. 262 p.

Montarroyos, A. V. V. 2000. Contaminação in vitro. ABCTP Notícias 36:5-10,

Murashige, T. \& Skoog, F. A. 1962. A revised medium for rapid growth and bio-assays with tobacco tissue cultures. Physiologia Plantarum 15:473-497.

Oliveira, R. P., Silveira, D. \& Silva, S. 2000. Efeito da desinfestação e do uso de meios de indicadores de contaminação na micropropagação de bananeira. Revista Brasileira de Fruticultura 22:57-61.

Oliveira, R. L. \& Faria, R. T. 2005. In vitro propagation of Brazilian orchids using traditional culture media and commercial fertilizers formulations. Acta Scientiarum 27:1- 5 .

Pansarin, E. R. \& Amaral, M. C. E. 2008. Reproductive biology and pollination mechanisms of Epidendrum secundum (Orchidaceae). Floral variation: a consequence of natural hybridization? Plant Biology 3:211 - 219,

Park, S. W., Jeon, J. H., Kim, H. S., Park, Y. M., Aswath, C. \& Joung, H. 2004. Effect of sealed and vented gaseous microenvironments on the hyperhydricity of potato shoots in vitro. Science Horticulturae 99:199-205.

Patricio, F. R. A., Borin, R. B. R. G. \& Ortolani D. B. 1995. Patógenos associados a sementes que reduzem a germinação e vigor. In (J.O.M. Menten - ed) Patógenos em Sementes: Detecção, Danos e Controle Químico. p. 137-160.

Pedroso-de-Moraes, C. 2000. Cultivo de orquídeas. Biblioteca Duse Rüegger Ometto, Araras. $130 \mathrm{p}$.

Pedroso-de-Moraes, C., Diogo, J. A., Pedro, N. P., Canabrava, R. I., de Assis Martini, G. \& Marteline, M. A. 2009a. Desenvolvimento in vitro de Cattleya loddigesii Lindley (Orchidaceae) utilizando fertilizantes comerciais. Revista Brasileira de Biociências 7:67-69.

Pedroso-de-Moraes, C., Santos, N. S., Massaro, R., Cordeiro, G. M. \& Souza Leal, T. 2009b. Desenvolvimento in vitro de Cattleya tigrina A. Richard. (Orchidaceae) utilizando fertilizantes comerciais. Ensaios e Ciência 13:57-65.

Pedroso-de-Moraes, C., Souza-Leal, T. D., Panosso, A. R. \& Souza, M. C. D. 2012. Efeitos da escarificação química e da concentração de nitrogênio sobre a germinação e o desenvolvimento in vitro de Vanilla planifolia Jack ex Andr. (Orchidaceae: Vanilloideae). Acta Botanica Brasílica 26:714-719.

Perin, A., Santos, R. H. S., Urquiaga, S., Guerra, J. G. M. \& Cecon, P. R. 2004. Produção de fitomassa, acúmulo de nutrientes e fixação biológica de nitrogênio por adubos verdes em cultivo isolado e consorciado. Pesquisa Agropecuária Brasileira 39:35-40.

Pinheiro, F. \& Barros, F. 2007. Morphometric analysis of Epidendrum secundum (Orchidaceae) in southeastern Brazil. Nordic Journal of Botany 25:129-136.

Pridgeon, A. M. 2014. Introduction. In Anatomy of the Monocotyledons: Orchidaceae (W. L. Stern ed.) Oxford University Press, Oxford. p. 1-42. 
Reddy, P. V., Nanjan, K. \& Shanmugavelu, K. G. 1992. In vitro studies in tropical orchids: seed germination and seedling growth. Coimbatori 6:75-78.

Rego-Oliveira, L. V. \& Faria, R. T. 2005. In vitro propagation of Brazilian orchids using traditional culture media and commercial fertilizers formulations. Acta Scientiarum Agronomy 27:1-5.

Rodrigues, D. T., Alvarez, V. V. H. \& Novais, R. F. 2002. Crescimento de um híbrido de orquídea em resposta a fertilizantes, doses e modo de aplicação. Rio de Janeiro. CD Fertibio.

Rodrigues, D. T., Novais, R. F., Alvarez, V. H., Dias, J. M. M., Otoni, W. C. \& de Albuquerque Villani, E. M. 2012a. Concentrações e composições químicas do meio nutritivo para o cultivo in vitro de orquídea. Revista Ceres 59:1-9.

. 2012b. Cultivo in vitro de plântulas de orquídea em meios com diferentes concentrações de fertilizante mineral. Revista Ceres 59:9-15.

Rodríguez, L., González, R., Díaz, A., Fajardo, E., Sánchez, E., Hernández, J., Castañeira, M. A., de la Cruz, G. \& González, J. 2005. Producción y recuperación de orquídeas silvestres cubanas. Disponível em:<http://www.secretariadeambiente.gov.co/sda/ libreria/pdf/ecosistemas/ restauracion/1_ar26.pdf $>$. Acesso em: 29 jun. 2014.

Rosa, M. D. \& Laneri, U. 1977. Modification of nutrient solutions for germination and growth in vitro of some cultivated orchids and the vegetative propagation of Cymbidium cultivars. American Orchid Society Bulletin 46:813-820.

Sebbenn, A. M., Seoane, C. E. S., Kageyama, P. Y. \& Vencovsky, R. 2000. Efeitos do manejo na estrutura genética de populações de caixeta (Tabebuia cassinoides). Scientia Florestalis 58:127-143.
Silva, A. L. L., Costa, J. D. L., Gollo, A. L., Dos Santos, J. D., Forneck, H. R., Biasi, A. L. \& Soccol, C. R. 2014. Development of a vinasse culture medium for plant tissue culture. Pakistan Journal of Botany 46: 2195-2202.

Sousa, G. C., Clemente, P. L., Isaac, V. L. R., Faria, S. P., de Siqueira Ferreira, A. \& de Cássia Campos, M. R. 2007. Contaminação Microbiana na Propagação in vitro de Cattleya walkeriana e Schomburgkia crispa. Revista Brasileira de Biociências 5:405-407.

Stancato, G. C. 2001. Produção de mudas de orquídeas a partir de sementes in vitro e sua viabilidade econômica: estudo de caso. Revista Brasileira de Horticultra Ornamental 7:25-33.

Stancato, G. C., Abreu, M. F. \& Furlani, A. M. C. 2008. Crescimento de orquídeas epífitas in vitro: adição de polpa de frutos. Bragantia 67:51-57.

Stancato, G. C. \& Faria, R. T. 1996. In vitro growth and mineral nutrition of lithophytic orchid Laelia cinnabarina Batem. (Orchidaceae): effects of macro and microelements. Lindleyana 11:41-43.

Torres A. C., Caldas L. S. \& Buzzo J. A. 1998. Cultura de Tecidos e Transformação Genética de Plantas, v.1-2. Embrapa, Brasília. 864 p.

Vaast, P., Zasoski, R. J. \& Bledsoe, C. S. 1998. Effects of solution pH, temperature, nitrate/ammonium ratios and inhibitors on ammonium and nitrate uptake by Arabica coffee in short term solution culture. Journal of Plant Nutrition 21:1551- 1564.

Vacin, E. \& Went, F. W. 1949. Some pH changes in nutrient solution. Bottanical Gazette 110:605-613.

Ventura, G. M., Dias, J. M. M., Teixeira, S. P., Carvalho, V. S., Motoike, S. Y., Novais, R. F. \& Cecon, P. R. 2002. Organogênese in vitro a partir de gemas apicais e axilares de plantas adultas de orquídeas do grupo Cattleya. Revista Ceres 47:613-628. 